\title{
Laminectomy by craniotome for huge spinal extradural arachnoid cyst: a case report
}

\author{
Bo Jin ${ }^{1}$, Ji-zong Zhao ${ }^{2}$, Han-bin Wang ${ }^{1}$, Ke-da Wang ${ }^{1}$, Long-qi Liu ${ }^{1}$ and Yi-bing Su ${ }^{1 *}$
}

\begin{abstract}
Background: Spinal extradural arachnoid cyst is extremely rare. The longest SEACs that have been reported in previous studies involved no more than 5 spinal segments. This study presents a case of SEAC diagnosed from T9 to $L 4$ and excised through a novel laminectomy/laminoplasty.

Case presentation: A 22-year-old female presented with a 5-year history of progressive paraparesis and numbness in both lower limbs. MRI revealed posterolateral epidural cystic mass extending from T9-L4 with a length of $190 \mathrm{~mm}$ and width of $15 \mathrm{~mm}$. The cyst was totally removed through surgery. The patient's symptom was completely relieved 1 year after the surgery. There was no recurrence, compression on the spinal cord, or kyphotic deformity based on MRI and CT taken 1 year after.

Conclusion: Spinal extradural arachnoid cysts are relatively uncommon but surgically curable causes of myelopathy. For symptomatic patients, early surgical intervention is suggested for restoring neurological functions. Performing laminectomy by using crainotome is safe and efficient.
\end{abstract}

Keywords: Extradural arachnoid cyst, Laminectomy, Laminoplasty, Spinal cord compression

\section{Background}

Spinal extradural arachnoid cyst (SEAC) is a rare cause of compressive myelopathy [1-3]. This lesion is reported to develop in any location, however most commonly occurs in posterior or posterolateral thoracic spine to the thoracolumbar area $[4,5]$. To our knowledge, SEAC usually relates with 2 to 5 spinal segments. The longest single SEAC reported involved 5 spinal segments [6]. In this article, we present a case of an extremely huge SEAC raging from T9-L4, which was excised by a novel surgical method in our center.

Meanwhile, we are expecting to introduce this novel technique of laminectomy/laminoplasty in the resection of SEAC with craniotome. The feasibility and availability of craniotome laminectomy/laminoplasty has not previously been thoroughly discussed in English literatures.

\footnotetext{
* Correspondence: Jinbo1000@126.com

'Department of Neurosurgery, Beijing Jishuitan Hospital, No.31 Xinjiekou East street, Xicheng District, Beijing 100035, China

Full list of author information is available at the end of the article
}

\section{Case presentation}

A 22-year-old female presented with a 5-year history of progressive paraparesis and numbness in both lower limbs complained of intermittent low back pain and urinary incontinence. She had no history of other illness, surgery, related trauma or family history of spine disease.

Neurologic physical examination showed weakness (power, 3/5) and hypesthesia in both lower limbs and hyporeflexivity of bilateral Achilles tendon reflexes. Spine MRI revealed posterolateral epidural cystic mass extending from T9-L4 with a length of $190 \mathrm{~mm}$ and width of $15 \mathrm{~mm}$ (Fig. 1).

The patient underwent surgery in a prone position with an informed consent. We implemented an innovative laminectomy to expose the entire cyst, in which two small holes that would accommodate the top plate of craniotome were opened on the lamina of T9 with highspeed drill. Top plate was placed on the epidural space so that the convicting laminas could be removed entirely. Given the fact the cyst was abnormally large, firstly we removed the laminas from T10-T11 and skived laminas overlying the cyst. After assuring the cyst was 


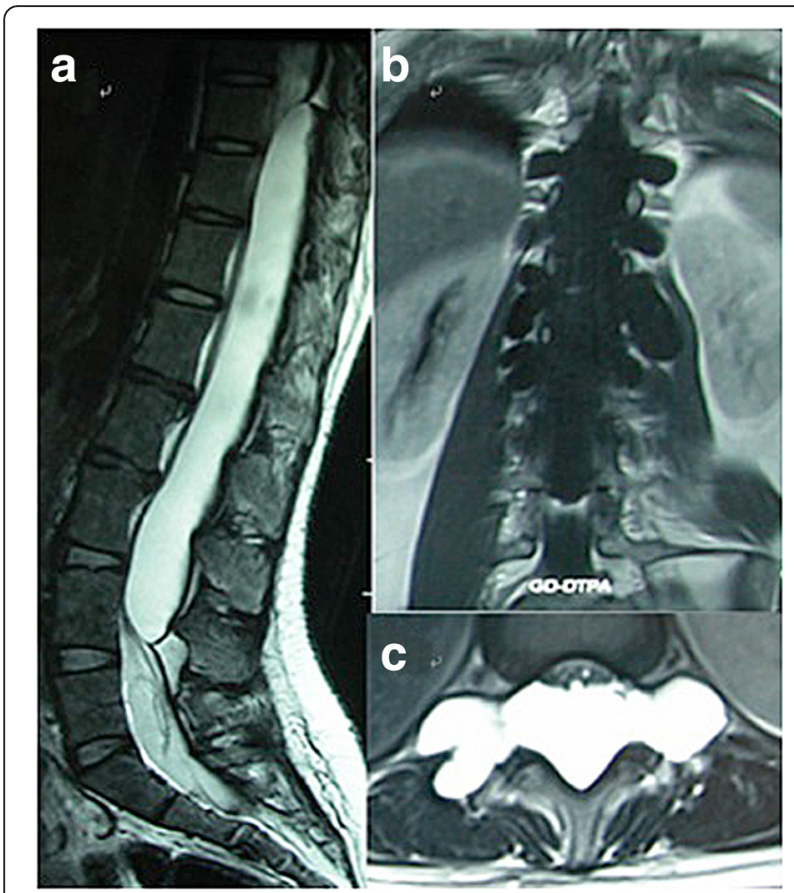

Fig. 1 a. Sagittal thoracolumbar region T1-weighted showing a spinal extradural arachnoid cyst from T9-L4. b. Coronal lumbar T1-weighted MRI showing compression of the spinal cord by a posteriorly placed arachnoid cyst. c. Axial lumbar T2-weighted MRI intact and adequate hemostasis we removed the rest part of laminas (L1-3) with the same technique. The cyst was intact after laminoplasty (Fig. 2). After a delicate dissection between the dura and the cyst, a stalk of cyst from head-end was separated and carefully explored, with no nerve root involved in the cyst under microscopic observation. An oval-liked dural defect approximately $5 \mathrm{~mm}$ sized at the right posterolateral side of the dural sac at T11 level, from which colorless CSF-like fluid flowed out, was repaired with absorbable silk 5-0. Titanium cables were used for laminoplasty. The wound was closed in a watertight fashion.

The patient's symptom was completely relieved 1 year after the surgery. There was no recurrence, compression on the spinal cord, or kyphotic deformity based on MRI and CT taken 1 year after (Fig. 3).

\section{Discussion}

Arachnoid cyst is a benign lesion comprising about $1 \%$ of spinal tumors and generally affects the thoracic region [1]. Clinical manifestation usually includes progressive spastic or flaccid paraparesis, sensory deficits, bowel incontinence and bladder incontinence $[4,5]$. The severity of symptom depends basically on cyst size $[4,7]$. The size of SEACs reported usually involves several spinal segments ranging from 3 to $5[1,4,8,9]$. In our case,

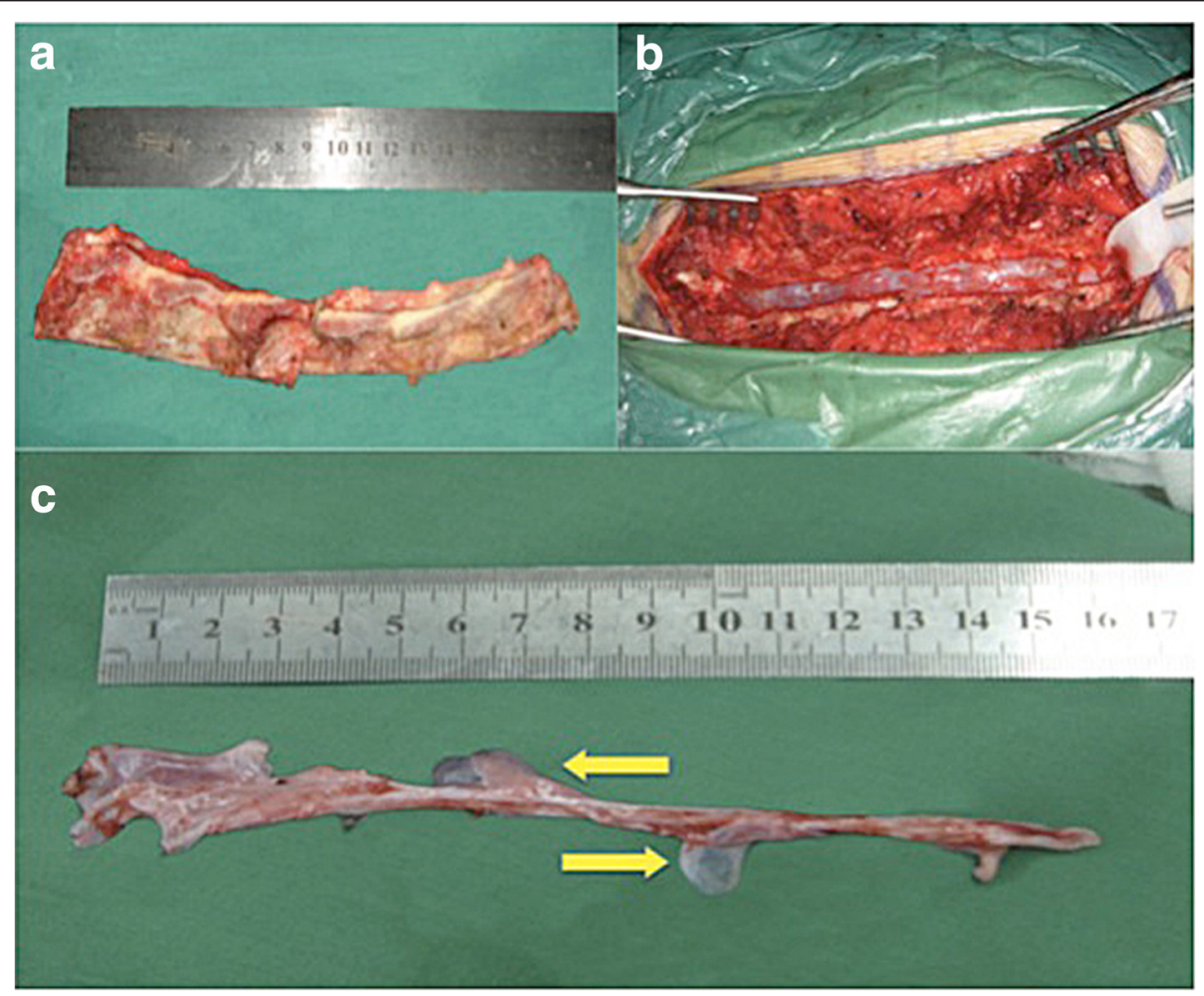

Fig. 2 a. The removed laminas and spinal processes. b A spinal extradural arachnoid cyst was entirely exposed after laminectomy. The cyst was intact. c The cyst was entirely removed. The yellow arrows point to the part growing into intervertebral foramen 


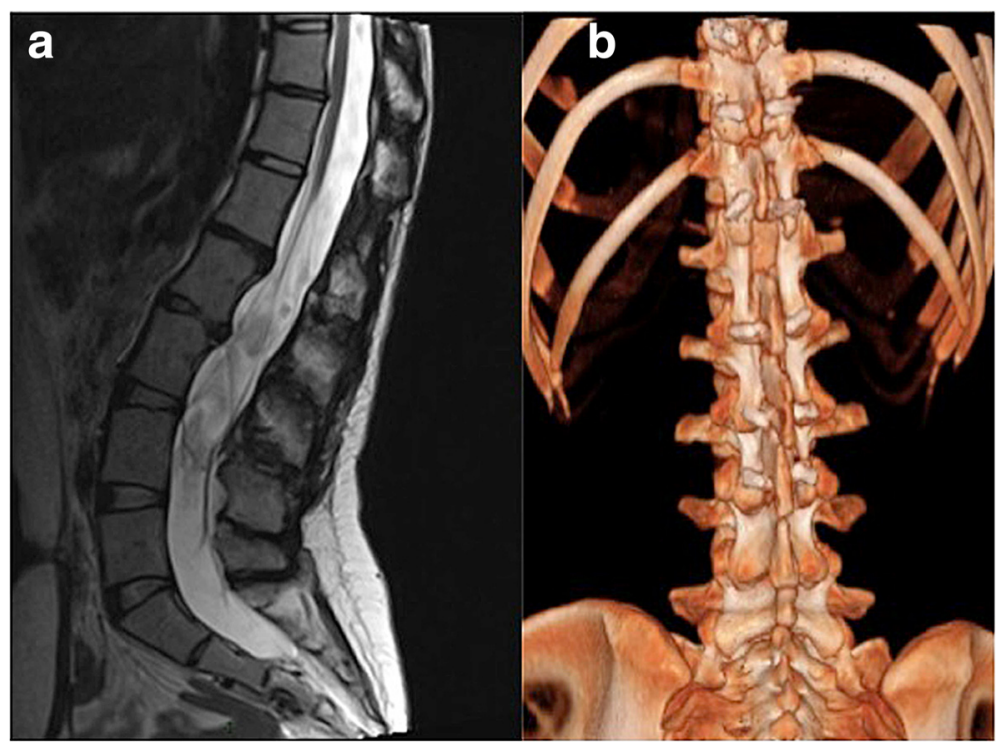

Fig. 3 a Sagittal T1-weighted MRI taken one-year later postoperatively. b Thoracolumbar region CT taken one-year later postoperatively

there were 8 segments related with the SECA, which might be the longest SEAC that have been reported up to now. The laminas became extremely thin because of the long-term compression. The patient also exhibited typical symptoms of myelopathy.

Several surgical options for treatment of SEAC have been proposed. The conventional laminectomy was performed by different tools such as bone osteotome or Tsaw $[1,10,11]$. Those methods provide excellent exposure and allow available space for safe excision of lesions. However, those techniques usually take a long time and moreover, such a wide laminectomy can easily injure the cord or rupture the cyst. In addition, lack of laminoplasty sacrifices the protective role of the posterior elements [5]. In our case, we used craniotome to perform the laminectomy. The author has been using this technique for two years and successfully excised hundreds of spinal lesions. Based on our experience, the advantages include less bleeding, less operating time and better maintenance of spinal stability. Because of the protective plate on top of the craniotome, the risk of damage to the dura and the wall of cyst may be significantly decreased. The total operating time was two and a half hours and the blood loss was approximately $250 \mathrm{ml}$ despite the immensity of the cyst. The cyst was intact after laminectomy, which could allow surgeon to identify anatomical structures easily and also be helpful to achieve the total resection.

The formation of epidural scar, especially the incidence of kyphotic deformity after conventional laminectomy has been reported to be $33-100 \%[8,11,12]$. Laminoplasty has been recommended to prevent these complications especially for cysts located on thoracic or lumbar spine $[6,11,12]$, and also helps to avoid excessive posterior elements loss. Titanium mini-plates were used for stabilizing laminas into their original positions in laminectomy. However, in our case 12 titanium cables were used because the author believed titanium cables provided better undergoing tension compared to tianuim mini-plates [13]. There was no kyphotic deformity or compression on the spinal cord based on the MRI taken 1 year after the surgery, which might be the evidence supporting this viewpoint.

\section{Conclusion}

Spinal extradural arachnoid cysts are relatively uncommon but surgically curable causes of myelopathy. The clinical symptoms of SEACs were variable and progressed slowly. For symptomatic patients, early surgical intervention is suggested for restoring neurological functions. Performing laminectomy by using crainotome is safe and efficient.

\section{Consent}

Written, informed consent was obtained from the patient for publication of this case report and accompanying images.

\section{Abbreviations}

MRI: magnetic resonance imaging; SEAC: spinal epidural arachnoid cyst.

\section{Competing interests}

The authors declare that they have no competing interests.

\section{Authors' contributions}

YS is the surgeon who performed the surgery. BJ contributed to the research in data collection and writing and he's also the surgon who participated the surgery. JZ contributed to this research with his guidance. HW, KW, LL, they were involved in the surgery and participated the data collection. The 
corresponding author is sincerely grateful for the contributions of all participate. All authors read and approved the final manuscript.

\section{Acknowledgement}

This research is sponsored by: The National Nature Science Fund of China Award Number: 61271367

\section{Author details}

'Department of Neurosurgery, Beijing Jishuitan Hospital, No.31 Xinjiekou East street, Xicheng District, Beijing 100035, China. ${ }^{2}$ Department of Neurosurgery, Beijing Tiantan Hospital, Beijing, China.

Received: 28 September 2015 Accepted: 3 May 2016

Published online: 18 May 2016

\section{References}

1. Lee SH, Shim HK, Eun SS. Twist technique for removal of spinal extradural arachnoid cyst: technical note. Eur Spine J. 2014;23:1755-60.

2. Choi SW, Seong HY, Roh SW. Spinal extradural arachnoid cyst. J Korean Neurosurg Soc. 2013;54:355-358.

3. Oh JK, Lee DY, Kim TY, Yi S, Ha Y, Kim KN, et al. Thoracolumbar extradural arachnoid cysts: a study of 14 consecutive cases. Acta Neurochir. 2012;154:341-8.

4. Kumar A, Sakia R, Singh K, Sharma V. Spinal arachnoid cyst. Journal of Clinical Neuroscience. 2011;18:1189-92.

5. Tureyen K, Senol N, Sahin B, Karahan N. Spinal extradural arachnoid cyst. The Spine Journal. 2009;9:10-5.

6. Woo Keun K, Keun Tae C, Seung Koan H. Spinal extradural arachnoid cyst: A case report. Korean J Spine. 2013;10:32-4.

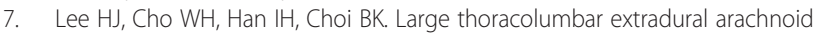
cyst excised by minimal skipped hemilaminectomy: a case report. Korean J Spine. 2013;10:28-31.

8. Kadono Y, Yuguchi T, Ohnishi Y, Iwatsuki K, Yoshimine T. A symptomatic spinal extradural arachnoid cyst with lumbar disc herniation. Case Rep Orthop. 2015;2015:250710.

9. Rahimizadeh A, Soufiani H. Intramedullary arachnoid cyst in association with cervical spondylosis: case report. The Spine Journal. 2013;13:21-5.

10. Kawahara N, Tomita K, Abdel-Wanis ME, Fujita T, Murakami H, Demura S. Recapping T-saw laminocostotransversoplasty for ventral meningiomas in the thoracic region. J Orthop Sci. 2009;14:548-55.

11. Qi W, Zhao L, Fang J, Chang X, Xu Y. Clinical characteristics and treatment strategies for idiopathic spinal extradural arachnoid cysts: a single-center experience. Acta Neurochirurgica. 2015;157:539-45.

12. Bond AE, Zada G, Bowen I, McComb JG, Krieger MD. Spinal arachnoid cysts in the pediatric population: report of 31 cases and a review of the literature. J Neurosurg Pediatr. 2012;9:432-41.

13. Doran SE, Papadopoulos SM, Miller LD. Internal fixation of the spine using a braided titanium cable: clinical results and postoperative magnetic resonance imaging. Neurosurgery. 1996:38:493-6.

\section{Submit your next manuscript to BioMed Central and we will help you at every step:}

- We accept pre-submission inquiries

- Our selector tool helps you to find the most relevant journal

- We provide round the clock customer support

- Convenient online submission

- Thorough peer review

- Inclusion in PubMed and all major indexing services

- Maximum visibility for your research

Submit your manuscript at www.biomedcentral.com/submit
Biomed Central 